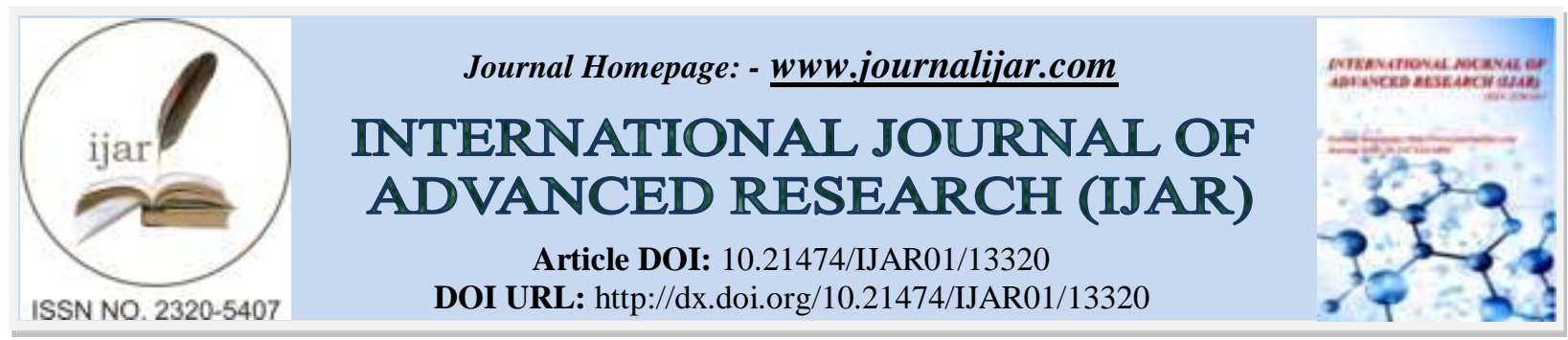

RESEARCH ARTICLE

\title{
THE EFFECT OF CO-OP APPROACH IN IMPROVING VISUAL MOTOR INTEGRATION SKILLS IN CHILDREN WITH LEARNING DISABILITY
}

Dr. Sheetal S. Gupta and Dr. Pritam V. Mehta

Senior Occupational Therapist. Rise and Shine, CDC, Mumbai, Maharashtra.

\section{Manuscript Info}

Manuscript History

Received: 25 June 2021

Final Accepted: 28 July 2021

Published: August 2021

\begin{abstract}
The importance of visual perception, motor coordination and visual motor integration (VMI) skills for school achievements has been shown in various studies. Cognitive orientation to daily occupational performance or CO-OP is an evidence-based approach that has been effective in children with developmental coordination disorder and autism spectrum. The present study evaluated the effect of CO-OP approach in improving VMI skills in children with learning disability. Sample of 58 children were included in the study. National Centre for Learning Disabilities (NCLD) Checklist was used as a screen tool and pre and post intervention Beery VMI and Canadian Occupational Performance Measures (COPM) was used as outcome measures.Occupational therapy program using $\mathrm{CO}-\mathrm{OP}$ approach, based on each child's individualized goals. children were thought global strategy of GO-PLAN-DO-CHECK the sessions were conducted for 12 weeks one hour a day three times a week. After 12 weeks post assessment was done using $\mathrm{t}$ test. There significant difference in pre and post CO-OP intervention. $\mathrm{p}$-value was found to be less than 0.0001 for VMI, COPM performance and satisfaction whereas, there was significant difference in motor coordination and visual perception component of Beery VMI. The result shows that CO-OP approach is effective in improving visual motor integration skills of children with learning disability.
\end{abstract}

Copy Right, IJAR, 2021,. All rights reserved.

\section{Introduction:-}

Visual perception provides children with base in their cognitive activities to adapt and control their behaviors. ${ }^{1}$ Visual perception skills are important in matching shapes, recognizing colors, and actualize tasks such as reading and writing. Mastery in movement, which is managed by cognitive and perceptual functions, is important for children to use their moment. Establishing coordination between visual perception and body movements, particularly hand movements, is called visual motor integration. ${ }^{2}$ Visual motor integration is the transformation of visual perception into motor output. The importance of visual perception, motor coordination and visual motor integration skills for school achievements has been shown in various studies. Many researchers have found a statistically meaningful relationship between writing problems and low visual perception, motor coordination and visual motor integration skills. ${ }^{2,3}$ Studies that have focused on the relationship between cognitive skills, and important indicator of school achievement, and visual motor integration found a relationship between cognitive skills and visual motor integration, visual perception and motor coordination skills. ${ }^{4}$ 
Cognitive orientation to daily operational performance or CO-OP is defined by Polatajko and Mandich as "clientcentered, performance based, problem solving approach that enables skill acquisition through a process of strategy use and guided discovery". ${ }^{5}$ CO-OP is an evidence-based approach that has been successful for children with developmental coordination disorder (DCD) and autism spectrum disorder (Rodger and Brandenburg, 2008). The main objective of CO-OP is skill acquisition in child-chosen tasks, development of cognitive strategies, and generalization and transfer of learning skills and strategies. There steps to the CO-OP approach include client chosen goals, dynamic performance analysis, cognitive strategy use, guided discovery, enabling principles, parent/significant other involvement and intervention format. Generally, the CO-OP approach is Go-Plan-Do-Check.

Competency in handwriting is considered as an important skill that the children have to acquire during their initial years at school. ${ }^{6}$ Present study, intends to evaluate the use of CO-OP approach in improving the VMI skills of children with learning disability. In present study attempt was, main to use Cognitive Occupational Performance Measure (COPM) considering the satisfaction and performance levels of the activity plan for the child.

\section{Methodology:-}

A prospective, quantitative, experimental study was conducted in occupational therapy unit of multidisciplinary setup. A sample of 58 patients were included using convenience sampling method. The inclusion criteria of the study were children between 9 to 14 years of age, both male and female, fulfilling criteria's as per LD checklist scores in either of the 3 domains as follows gross and fine motor skills: $\geq 6$ language: $\geq 26$ reading: $\geq 22$ written language: $\geq 18$ math: $\geq 22$ socio/emotional: $\geq 22$ attention: $\geq 16$ others: $\geq 20$. Exclusion criteria of the study were children with physical disorders former condition such as autism, ADHD, severe and profound mental retardation etc. Children taking additional tuitions for special coaching for improving handwriting.

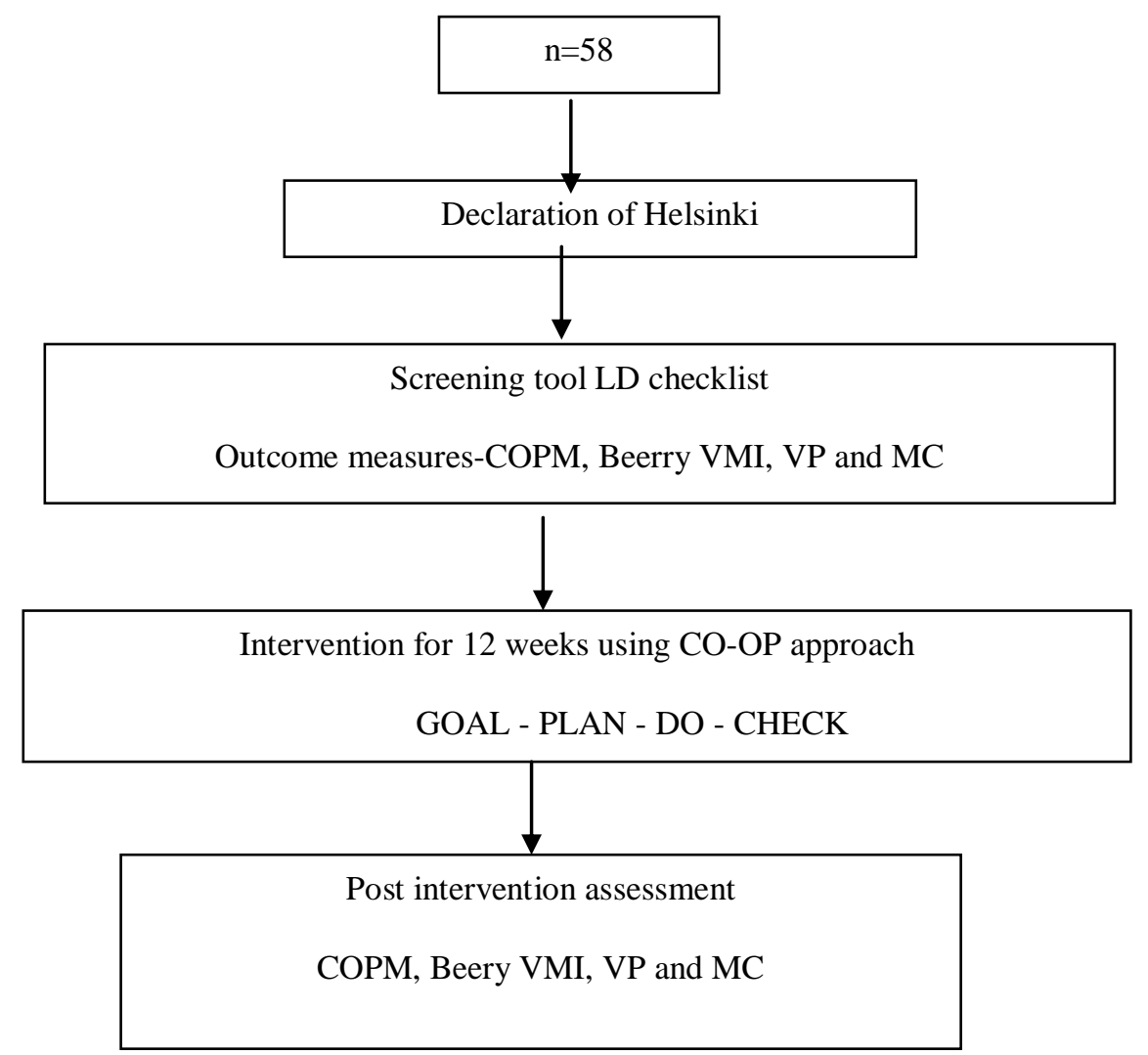

After selecting the patients, written informed consent and assent was taken from the parent and the children in the best language understood by them.

The research was conducted adhering to the principles of the" Declaration of Helsinki guidelines". ${ }^{7}$ 


\section{Tools Equipment's and Outcome Measures LD checklist}

LD checklist was developed by National center for learning disabilities (NCLD; 2007). ${ }^{8}$ LD Checklist is design as a tool to understand potential science of the learning disabilities. The more characteristics checked, the more likely the individual shows signs of learning disabilities. It has 8 domains namely gross and fine motor skills, language, reading, written language attention, math, social/emotional and others. It was used for screening the children having learning difficulty, it is a questionnaire which is divided into domains. According to the age group subject who scored 26 or more in language 22 or more in reading 18 or more in written language 22 or more at math and for social emotional 16 or more for attention were included for study. ${ }^{9}$

\section{Beery VMI}

The Beery VMI was developed by Keith E. Berry, Natasha A. Beery and Norman A. Buktenica 2009 and in 2010. The test can be administered from ages 2 through 18. It measures the extent to which individuals can integrate their visual and motor abilities. This is a paper pencil test, which is carried out in a well-lighted, ventilated and destruction free room. This assessment can help identify children who may need special assistance, to obtain needed services for them, to test the effectiveness of educational and other interventions and to advanced research. The respondent is asked to copy geometry drawings on to a form. The drawings are presented in order of increasing difficulty. Distinct visual perception and motor coordination subtests are included, making it possible to test one skill set to the exclusion of the other. Scoring is completed on the form. Visual motor integration, visual perception, motor coordination psychometric properties: Mean content reliability $=0.93-0.96$ and mean person reliability $=0.83$ 0.84 Internal consistency $=0.95$, internal consistency using Cronbach's Alpha $=0.96$ (very good for clinical purposes) interrater reliability $=0.93 .^{10}$

\section{Canadian occupational performance measure (COPM)}

The COPM scale is a client centered, occupational focus outcome measures and it is used for semi-structured interview format and structure scoring method. It evaluates children perception of their perceived changes in occupational performance overtime. Caregivers identify issues in self-care, productivity and leisure and read performance and satisfaction scores ranking from 1 to 10. In the current study COPM is given to parents to rate their children's handwriting performance and satisfaction. ${ }^{11}$

\section{Cognitive orientation to daily occupational performance (CO-OP) Intervention}

Cognitive orientation to daily occupational performance (CO-OP; CO-OP Approach) is a client centered performance-based treatment approach for children and adults who experience difficulties performing the skills they want to, need to or expected to perform. CO-OP is a specifically tailored, active client-centered approach that engages the individual at the meta-cognitive level to solve performance problems. ${ }^{5}$

CO-OP intervention was given to the children based on each individualized child set goals. Children were taught global strategies of GOAL-PLAN-DO-CHECK. ${ }^{12}$ They were taught to apply these strategies during handwriting practice sessions. The sessions for each child included 45 minutes to 1 hour 3 times a week for 12 weeks. The children were taught generalization of the learnt strategies by writing on textured material other than paper, such as writing on raised lines, tracing and writing on thickened butter paper and writing on the board. Home program focusing on handwriting skills as given to parents. At the end of 12 weeks, posttest was taken using Beery VMI, VP and MC, and parents were given COPM, to rate the performance and satisfaction of handwriting performance of the children. All the children involved in the study where able to apply the global strategies of Goal, Plan, Do and Check.Goal The children were initially oriented to the process of global strategies. The children were able to identify the larger prints, the reversal of letter in their handwriting, which was set as their individual goals for the 12 weeks of intervention. The children set goals such as letters should be big in size, the spacing should improve, the reversal of letters should be corrected, to improve legibility etc.Plan The strategy of planning was taught to each child according to the goal they had set. The children were actively involved in planning strategies like on which surface writing would be easier for them to achieve their goals. Such as writing on four-line notebook or a two-line notebook with larger space in between. Do Do was the task performance. The children were asked to copy lines from board, from textbooks, from story books. They were made to write on different texture such as on blackboard, on paper, on worksheets, on raised lines, on butter paper, on the notebooks of their choice, on chart papers with different angle lines and shapes. These activities made the children to stay focused on their task because of novel writing surfaces.Check Checking strategy was taught by making the children compare their handwriting to the previous days or previous week and it helped them to see if they are improving or still needing improving. The 
children were rewarded with a star if they show improvement and where encourage to follow the same in other setting such as classroom. Other children were motivated to keep trying for the next week.Towards the later sessions the children were able to apply this strategy by themselves during task performance. The children were taught generalization and transfer of learning so that they can apply the learnt skills in other settings such as home and classroom.

\section{Procedure}

After obtaining consent from the 58 patients baseline evaluation was done using COPM, Beery VMI, VP, and MC. Sessions were conducted in the center 1:1 basis for 45 minutes to 1 hour 3 times a week for 12 weeks. Parents were also given home program focusing on COPM performance component of writing. Therapy program was designed using CO-OP approach activities were divided into parts of goal - plan -do -check e.g., firstly the child was motivated and taught about how to hold a pencil and tricks for the same. Once step was achieved the next step was executing that one thing like writing two letter words, the formation of letter which was followed by planning the formations of words to write that one 2 letter word, once the child has achieved that stage therapist guides the child to about checking all the work, he/she has done which falls into completing about check of the approach used.

At the end of 12 weeks post-test was taken using Berry VMI, VP and MC, and parents were given COPM, to rate the performance and satisfaction of handwriting performance of the children.

\section{Results:-}

Data analysis was done using SPSS 16. Out of 58 patients 38 were boys and 20 were girls. The mean age of patient was $11.1 \pm 1.94$. As seen in table no. 2 comparison between pre and post CO-OP intervention VMI assessment was done. Pre-CO-OP intervention the mean score for VMI, VP and MC was $19.4 \pm 3.63,20.93 \pm 3.63$, and 19. $72 \pm 3.73$ respectively and post CO-OP intervention means scores were $21.53 \pm 2.84,22.47 \pm 2.05$ and $23.41 \pm 2.6$, paired $t$ test was done and there was statistically significant difference with $\mathrm{p}$ value $<0.0001$ (figure 1). Also, mean score of COPM was compared and there was significant difference with p value $<0.0001$ (table 2 and figure 2).

Table 1:- Demographics.

\begin{tabular}{|l|l|l|l|l|}
\hline $\mathrm{n}$ & Males & Females & Mean age & SD \\
\hline 58 & 38 & 20 & 11.1 & 1.94 \\
\hline
\end{tabular}

Table 2:- comparison of pre and post interventions sources of VMI,VP and MC.

\begin{tabular}{|c|c|c|c|c|c|c|c|c|c|}
\hline $\begin{array}{l}\text { Group } \\
\text { VMI }\end{array}$ & Mean & SD & SEM & $\begin{array}{l}95 \% \\
\mathrm{Cl} \\
\text { Lower }\end{array}$ & $\begin{array}{l}95 \% \\
\mathrm{Cl} \\
\text { Upper }\end{array}$ & $\mathrm{df}$ & $\mathrm{t}$ & $\begin{array}{l}\text { Standard } \\
\text { error of } \\
\text { difference }\end{array}$ & $\mathrm{p}$ value \\
\hline Pre & 19.4 & \pm 3.63 & 0.48 & \multirow[t]{2}{*}{-2.63} & \multirow[t]{2}{*}{-0.06} & \multirow[t]{2}{*}{57} & \multirow[t]{2}{*}{2.1021} & \multirow[t]{2}{*}{0.64} & \multirow[t]{2}{*}{0.04} \\
\hline Post & 20.74 & \pm 4.83 & 0.63 & & & & & & \\
\hline Pre & 20.93 & \pm 3.13 & 0.41 & \multirow[t]{2}{*}{-2.15} & \multirow[t]{2}{*}{-0.92} & \multirow[t]{2}{*}{57} & \multirow[t]{2}{*}{4.9916} & \multirow[t]{2}{*}{0.307} & \multirow[t]{2}{*}{0.0001} \\
\hline Post & 22.47 & \pm 2.05 & 0.27 & & & & & & \\
\hline Pre & 20.02 & \pm 4.02 & 0.53 & \multirow[t]{2}{*}{-3.91} & \multirow[t]{2}{*}{-0.47} & \multirow[t]{2}{*}{57} & \multirow[t]{2}{*}{2.5441} & \multirow[t]{2}{*}{0.861} & \multirow[t]{2}{*}{0.0137} \\
\hline Post & 22.21 & \pm 5.84 & 0.77 & & & & & & \\
\hline
\end{tabular}

Graph 1:- Comparison of main scores of Beery VMI, VP and MC components.

\section{Comparison of mean scores of Berry VMI, VP and MC} components.

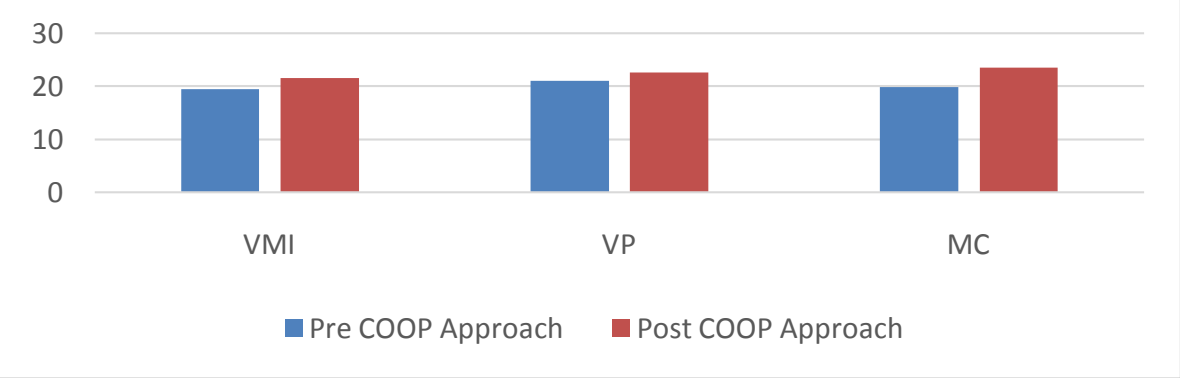


Table 3:- Comparison of pre and post intervention scores of COPM components.

\begin{tabular}{|c|c|c|c|c|c|c|c|c|c|}
\hline Group & Mean & SD & SEM & df & $\mathrm{t}$ & SED & $\begin{array}{l}95 \% \mathrm{Cl} \\
\text { Lower }\end{array}$ & $\begin{array}{l}95 \% \mathrm{Cl} \\
\text { Upper }\end{array}$ & $\begin{array}{l}\mathrm{P} \\
\text { Value }\end{array}$ \\
\hline $\begin{array}{l}\text { Pre COPM } \\
\text { performance }\end{array}$ & 2.49 & \pm 0.66 & 0.087 & \multirow[t]{2}{*}{57} & \multirow[t]{2}{*}{19.09} & \multirow[t]{2}{*}{0.16} & \multirow[t]{2}{*}{-3.39} & \multirow[t]{2}{*}{-2.75} & \multirow[t]{2}{*}{0.0001} \\
\hline $\begin{array}{l}\text { Post COPM } \\
\text { performance }\end{array}$ & 5.53 & \pm 0.98 & 0.129 & & & & & & \\
\hline $\begin{array}{l}\text { Pre COPM } \\
\text { satisfaction }\end{array}$ & 2.52 & \pm 0.68 & 0.089 & \multirow[t]{2}{*}{57} & \multirow[t]{2}{*}{19.79} & \multirow[t]{2}{*}{0.15} & \multirow[t]{2}{*}{-3.35} & \multirow[t]{2}{*}{-2.73} & \multirow[t]{2}{*}{0.0001} \\
\hline $\begin{array}{l}\text { Post COPM } \\
\text { satisfaction }\end{array}$ & 5.57 & \pm 0.98 & 0.129 & & & & & & \\
\hline
\end{tabular}

Graph 2:- Comparison of mean scores of COPM performance and satisfaction components.

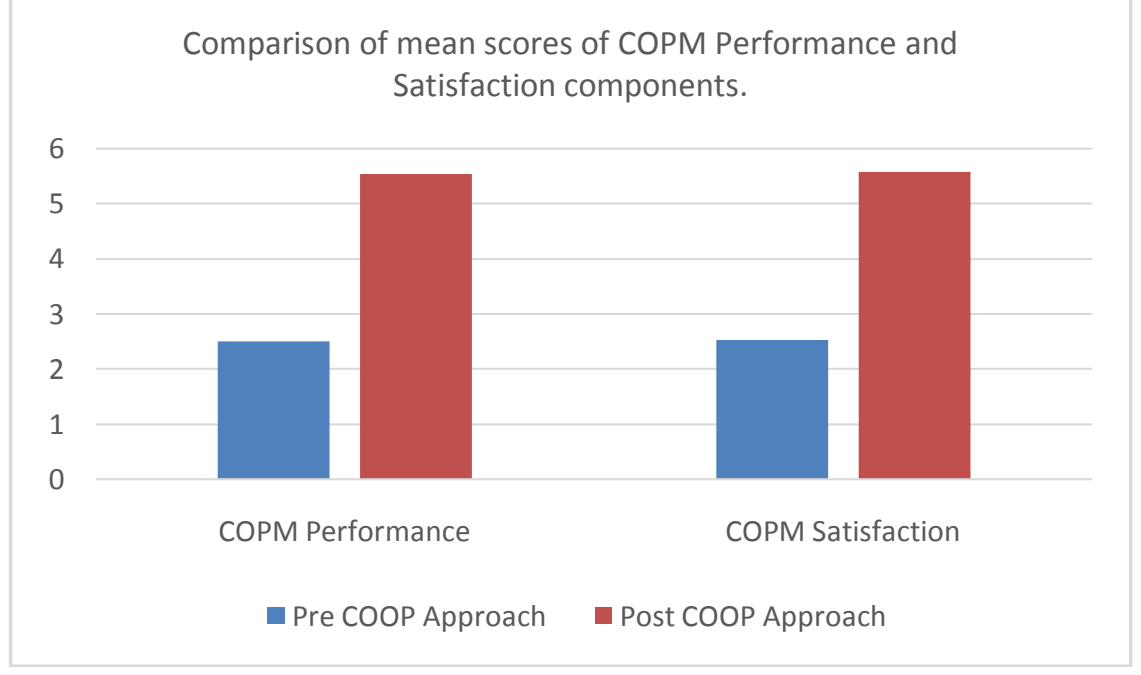

\section{Discussion:-}

Learning disabilities has been considered as a diversified group of disorder displayed by impacting the ability of acquisition and use of listening, speaking, reading, writing, reasoning, or mathematical abilities. Occupational therapist has been actively working with children who have issues with handwriting and reading skills using various approaches and techniques. This study was intended for the effect of CO-OP approach in in improving visual motor integration (VMI) skills in children with learning disability. It is found that CO-OP is an effective approach in improving VMI skills of children with learning disability. In our study we took 58 children between 9-14 years of age.

There was significant difference in post CO-OP intervention in all the component of berry VMI, VP and MC and also COPM performance and satisfaction. This is supported by the Jaywant $\mathrm{S}$ et al, authors proposed that this study promotes use of CO-OP in occupational therapy intervention for improvement of handwriting performance skills. ${ }^{13}$ During the initial period of treatment GOAL was decided which was followed up by planning of treatment and lastly the child has to perform and assess themselves which facilitated / promoted/ enhanced the executive functions skills. Thornton et al also found significant changes in in the performance and satisfaction ratings on COPM which provides valuable information in terms of the child and parent perception of their improvement over the intervention period. $^{14}$

Similarly, in the study conducted by Sara Mc wen and Helena Polatajko conducted RCTs using CO-OP and COPM. Three main activities were selected by COPM and goal-plan-do-check strategy was used alternatively as the main problem-solving framework to facilitate activity acquisition. The participant woodwork on one or more of the three goals set guided by the therapist coma to discover a plan to achieve the goal. The participant would then do the plan and subsequently check to see if the plan was implemented and if it worked-that is, weather the goal was achieved. If the goal was not achieved, the participant was guided to analyze the performance breakdown and modify or create a new plan. Within the plan phase, the therapist uses guided discovery to help the participant analyze the 
performance breakdown and discover domain-specific strategies to overcome the particular performance problems off the client with that activity. Thus, the plan- do- check process was repeated until the performance breakdown was successfully overcome, repeatedly; then, going to the next performance breakdown until all were overcome and the goal was achieved, repeatedly. In the present study the particular task for the child was identified through COPM and taken for $\mathrm{CO}-\mathrm{OP}$ and taken to improve $\mathrm{CO}-\mathrm{OP}$ strategies. The children scored statistically significant difference post CO-OP approach as it involves active engagement in planning organizing and monitoring activities. As it is supported by literature where in in, exercise is the intentional engagement in the physical activity and the task like of writing, completing books engages the child in in the same. Also, physical activities encompass all forms of movements produced by skeletal muscles. ${ }^{15}$

The positive changes in post CO-OP intervention are encouraging, this can be because after treatment there might be a growing awareness of child's own situation and level of skills for managing various life situation independently. ${ }^{14}$ The children are perform well that maybe because CO-OP approach contributes to transfer of learning. Transfer of skills learn intervention is a novel skill which is necessary to achieve optimal long-term behavioral regulation and metacognition ability e of the children with executive functioning at school and at home. In CO-OP approach the children is explicitly work upon the generalization and transfer of skills in various environment. The use of global strategy is enhancing the child's ability to solve new activity problem through meta-cognitive thinking such as planning, monitoring and evaluating.

The skills of VMI, VP and MC also improved post CO-OP intervention. This is in contrast with the study done by ward which says that VMI scores remained the same in the post test as the pre-test which can be attributed to the fact that the children in this study received only 10 weeks of intervention unlike 12 weeks. And also due to the fact that they had other occupational goals also set by the children unlike purely focusing on handwriting. ${ }^{16}$

The sensitivity of the CO-OP approach over the conventional occupational therapy is found in all the assessment tests. The article by Klingner $J$ et al in her study on collaborative strategic reading (CSR) in which the child is been taught about the different strategies like preview text in which child has read the paragraph, which will activate his/her prior knowledge and will stimulate interest about topic and facilitate making predictions. Next step is during reading in which strategy like click and clunk is used later which is followed up by other strategies like vocabulary fix up, read-pause-reflect, partner retell. Similarly, CO-OP was developed to help children with learning disabilities and has positively impacted the reading comprehension, develops cooperative skills and enhances overall performance and achievement. ${ }^{17}$ This shows that CO-OP is a promising approach for enabling the children to achieve personal goals as the COPM performance and satisfaction scores post CO-OP intervention was statistically significant with $\mathrm{p}$ value $<0.0001$.

Engagement is seen as closely related to meaningfulness and meaning, purpose and choice is of essential importance to the value that people assign to different situations in life. Studies have shown that if a person is involved in the intervention process, his or her engagement increases, and also that goal-setting in itself enhances the person's engagement in the intervention. ${ }^{18}$ In intervention group activities were focusing on the fine motor activities and to recite the words with relation to phonics where is the activities in CO-OP approach focused on skill acquisition, cognitive-strategy use, generalization of the activity learned to new situations, and transfer of a goal strategy learned to solve new problems. The phone and decoding abilities of the children in CO-OP approach group where focus on the word recognition ability like decoding, phonemic awareness, word attack skills. The children were taught skills in an explicit direct fashion.

\section{Limitations:-}

The attention Span of the children was inconsistent for the entire one hour of intervention. The study was restricted to unicentric study. The carryover effect of intervention is not studied.

\section{Conclusion:-}

Visual motor integration skills are an important in academic performance of children. These skills are directly associated with handwriting and reading outcomes. The use of COPM has facilitated identifying the significant areas of child in academic functions. This has eased formulating the goals for the child pertaining to CO-OP strategies used during intervention has announced improvement in VMI skills. From this study we can conclude that CO-OP is 
an effective approach in improving VMI skills of children with issues in handwriting. As well as there is high parent satisfaction as seen in COPM scale.

\section{Further Recommendations:-}

Multicenter study for generalization of results can be conducted for longer duration of study. Post intervention correlating with academic achievement of children can be done to assess the post therapy effect of CO-OP approach.

\section{References:-}

1. Case Smith, O Brien Occupational Therapy for children, $6^{\text {th }}$ edition, pg.no: $173-174$.

2. Dibek E. Implementation of visual motor ability enhancement program for 5 years old. Procedia- Social and Behavioral Science. 2012 January 1:46:1924-32.

3. Branhardt CN, Borsting EJ. The relationship between visual motor integration and spatial organization of written language and math (Dr recitations California State University Fullerton).

4. Coallier M, Rouleau N, Bara F, Morin MF. Visual-motor skills performance on Beery VMI: A study on Canadian kindergarten children. The open journal of Occupational Therapy. 2014; 2(2):4.

5. Mandich A, Polatajko HJ. Enabling occupation in children: The cognitive orientation to daily occupational performance (CO-OP) approach. Canadian association association of occupational Therapist: 2004.

6. Feder KP, Majnemar A, Bourbonnais D, Platt R, Blayney M, Synnes A. Handwriting performance in preterm children compared with term peers at age 6 to 7 years. Dev Med Child Neurol 2005; 47(3):163-70.

7. General Assembly of World Medical Association. World Medical Association Declaration of Helsinki: ethical principles for medical research involving human subjects. The Journal of American College of dentists. 2014;81 (3): 14-8.

8. National Centre for Learning Disability, U.S. National Centre for Learning Disabilities NCLD. United States, 2007.

9. Ashraf F, Najam N. Validation of learning disabilities checklist in public sector schools of Pakistan. Pakistan journal of Psychological Research. 2014 Dec 31:223-24.

10. Keith B, Natasha B, Norman B, Beery-Buktenica Developmental Test of Visual-Motor Integration (MVPT-4), 6th edition; 2010.

11. Law M, Baptiste S, McColl M, Opzoomer A, Polatajko H, Pollock N. The Canadian occupational performance measure and outcome measure for occupational therapy Canadian journal of occupational therapy. 1990 April; 57(2):82-7.

12. Helene J. Polatajko, AngelaD. Mandich, Linda T.Miller and Jennifer J.Macnab cognitive orientation to daily occupational performance (CO-OP), physical and occupational therapy in pediatrics, 2001; 20: 2-3, 83-106.

13. Rajul Daftary, Shailaja jaywant. To study the efficacy of cognitive orientation to occupational performance approach in improving handwriting skills in school going children. Indian occupational journal. 2015-9:47, 89-96.

14. Sangster CA, Beninger C, Polatajko HJ, Mandich A. Cognitive strategy generation in children with developmental coordination disorder. Canadian journal of occupational therapy.2005 Apr;72(2):67-77.

15. McEwen S, Polatajko H, Baum C, Rios J, Corone D, Doherty M, Wolf T. Combined cognitive-strategy and taskspecific training improve transfer to untrained activities in subacute stroke: an exploratory randomized controlled trial. Neurorehabilitation and neural repair.2015 Jul; 29(6):526-36.

16. Ward A, Rodger S. The application of cognitive orientation to daily occupational performance (CO-OP) which children 5-7 years with developmental coordination disorder. British journal of occupational therapy.2004 Jun; 67(6):256-64.

17. Klingner J. \& Vaughn S. (1999). Promoting reading comprehension, content learning, and English equation through collaborative strategic reading (CSR). The Reading Teacher, 52. No. 7

18. Peny- Dahlstrand M, Bergqvist L, Hofgren C, Himmelmann K, Ohrvall AM. Potential benefits of the cognitive orientation to daily occupational performance approach in young adults with spina bifida or cerebral palsy: a feasibility study. DisabilRehabil. 2020;42(2):228-39. 